\title{
Mediastinum Soft Tissue Tumors
}

The following is the list of mediastinal soft tissue tumors (alphabetical order): for details on each single neoplasm $\rightarrow$ see dedicated sections.

Soft tissue tumors of the mediastinum should be differentiated from other mediastinal masses, such as thymic tumors (thymoma, thymic carcinoma), germ cell tumors (teratoma, seminoma, non-seminomatous germ cell tumor), lymphomas, parathyroid adenoma, intrathoracic goiter, cystic lesions (bronchogenic, pericardial, enteric), meningocele, as well as neurogenic neoplasms (i.e., paraganglioma, ganglioneuroma, neuroblastoma and ganglioneuroblastoma) that are not covered in this book.

\begin{tabular}{l|l}
\hline Tumor & Notes \\
\hline Angiomyolipoma & - \\
\hline Chordoma & $\rightarrow$ See Chap. 92 \\
\hline Hemangioendothelioma & - \\
\hline Hemangioma & - \\
\hline Inflammatory myofibroblastic tumor & - \\
\hline Leiomyosarcoma & - \\
\hline Lipoma & - \\
\hline Liposarcoma & - \\
\hline Lymphangioma & - \\
\hline Malignant peripheral nerve sheath tumor & - \\
\hline Meningioma & $\rightarrow$ See Chap. 79 \\
\hline Neurofibroma & - \\
\hline Primitive neuroectodermal tumor & PNET \\
\hline Rhabdomyosarcoma & - \\
\hline Schwannoma & - \\
\hline Solitary fibrous tumor & - \\
\hline Synovial sarcoma & - \\
\hline
\end{tabular}

